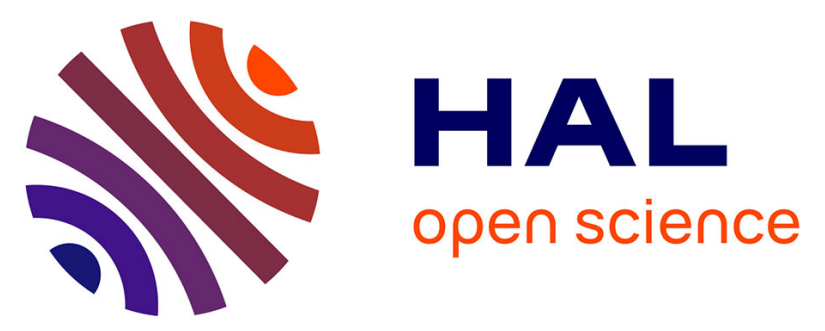

\title{
Primary vitreoretinal lymphoma: short review of the literature, results of a European survey and French guidelines of the LOC network for diagnosis, treatment and follow-up
}

Denis Malaise, Caroline Houillier, Valérie Touitou, Sylvain Choquet, Karim

Maloum, Magali Le Garff-Tavernier, Frédéric Davi, Anne Vincent-Salomon, Loïc Feuvret, Khê Hoang-Xuan, et al.

\section{- To cite this version:}

Denis Malaise, Caroline Houillier, Valérie Touitou, Sylvain Choquet, Karim Maloum, et al.. Primary vitreoretinal lymphoma: short review of the literature, results of a European survey and French guidelines of the LOC network for diagnosis, treatment and follow-up. Current Opinion in Oncology, 2021, 33 (5), pp.420 - 431. 10.1097/cco.0000000000000776 . hal-03559355

\section{HAL Id: hal-03559355 \\ https://hal.science/hal-03559355}

Submitted on 20 Feb 2022

HAL is a multi-disciplinary open access archive for the deposit and dissemination of scientific research documents, whether they are published or not. The documents may come from teaching and research institutions in France or abroad, or from public or private research centers.
L'archive ouverte pluridisciplinaire HAL, est destinée au dépôt et à la diffusion de documents scientifiques de niveau recherche, publiés ou non, émanant des établissements d'enseignement et de recherche français ou étrangers, des laboratoires publics ou privés. 


\section{Current Opinion in Oncology}

Primary vitreoretinal lymphoma: short review of the literature, results of a European survey and French guidelines of the LOC network for diagnosis, treatment and follow-

up

--Manuscript Draft--

\begin{tabular}{|c|c|}
\hline Manuscript Number: & CCO330516R1 \\
\hline Article Type: & Review Article \\
\hline Corresponding Author: & $\begin{array}{l}\text { Carole Soussain, MD, PhD } \\
\text { Institut Curie, Site de Saint-Cloud } \\
\text { Saint-Cloud, FRANCE }\end{array}$ \\
\hline \multicolumn{2}{|l|}{$\begin{array}{l}\text { Corresponding Author Secondary } \\
\text { Information: }\end{array}$} \\
\hline Corresponding Author's Institution: & Institut Curie, Site de Saint-Cloud \\
\hline \multicolumn{2}{|l|}{ First Author Secondary Information: } \\
\hline \multirow[t]{7}{*}{ Order of Authors: } & Denis Malaise, MD \\
\hline & Caroline Houillier, MD \\
\hline & Valérie Touitou, MD, PhD \\
\hline & Sylvain Choquet, MD \\
\hline & Karim Maloum, MD, PhD \\
\hline & Magali Le Garff-Tavernier, PharmD, PhD \\
\hline & Carole Soussain, MD, PhD \\
\hline
\end{tabular}




\section{Primary vitreoretinal lymphoma: short review of the literature, results of a European survey and French guidelines of the LOC network for diagnosis, treatment and follow- up}

Authors:

Malaise Denis, Houillier Caroline, Touitou Valérie, Choquet Sylvain, Maloum Karim, Le Garff-Tavernier Magali, Davi Frédéric, Vincent-Salomon Anne, Feuvret Loïc, Hoang-Xuan Khê, Cassoux Nathalie, Soussain Carole. On behalf of the LOC network and the ERNEuroBloodNet.

Denis MALAISE, MD, Institut Curie, Ophthalmology Department, Paris France; Institut Curie, PSL University, Inserm U1288, Laboratoire d'Imagerie Translationnelle en Oncologie, 91400 Orsay, France; Member of European Reference Network on Rare Hematological Diseases (ERN-EuroBloodNet)

Caroline HOUILLIER, MD, Sorbonne Université, IHU, ICM, Department of NeuroOncology, Hôpital Pitié-Salpêtrière, Assistance Publique-Hôpitaux de Paris, Paris, France, and French Network for Oculo-cerebral Lymphomas (LOC network)

Valérie TOUITOU, MD, PhD, Sorbonne Université, Department of Ophthalmology, Hôpital Pitié-Salpêtrière, Assistance Publique-Hôpitaux de Paris, Paris, France, and French Network for Oculo-cerebral Lymphomas (LOC network)

Sylvain CHOQUET, MD, Sorbonne Université, Department of Clinical Hematology, Hôpital Pitié-Salpêtrière, Assistance Publique-Hôpitaux de Paris, Paris, France, and French Network for Oculo-cerebral Lymphomas (LOC network)

Karim MALOUM, MD, PhD, Sorbonne Université, Department of Biological Hematology, Hôpital Pitié-Salpêtrière, Assistance Publique-Hôpitaux de Paris, Paris, France, and French Network for Oculo-cerebral Lymphomas (LOC network)

Magali LE GARFF-TAVERNIER, PharmD, PhD, Sorbonne Université, Department of Biological Hematology, Hôpital Pitié-Salpêtrière, Assistance Publique-Hôpitaux de Paris, Paris, France, and French Network for Oculo-cerebral Lymphomas (LOC network)

Frédéric DAVI, MD, PhD, Sorbonne Université, Department of Biological Hematology, Hôpital Pitié-Salpêtrière, Assistance Publique-Hôpitaux de Paris, Paris, France, and French Network for Oculo-cerebral Lymphomas (LOC network)

Anne VINCENT-SALOMON, MD, PhD, Institut Curie, PSL Research University, Department of Pathology, Department of Theranostic and Diagnostic Medicine, Paris, France

Loïc FEUVRET, MD, Sorbonne Université, Department of Radiotherapy, Hôpital PitiéSalpêtrière, Assistance Publique-Hôpitaux de Paris, Paris, France, and French Network for Oculo-cerebral Lymphomas (LOC network) 
Khê HOANG-XUAN, MD, PhD, Sorbonne Université, Department of Neuro-Oncology, Hôpital Pitié-Salpêtrière, Assistance Publique-Hôpitaux de Paris, Paris, France, and French Network for Oculo-cerebral Lymphomas (LOC network)

Nathalie CASSOUX, MD, PhD, Institut Curie, Ophthalmology Department, Paris France; Université de Paris, UMR 144 CNRS; Member of European Reference Network on Rare Hematological Diseases (ERN-EuroBloodNet), and French Network for Oculo-cerebral Lymphomas (LOC)

Carole SOUSSAIN, MD, PhD, Institut Curie, Site de Saint-Cloud, Hematology Department, INSERM U932 Institut Curie, PSL Research University, Paris, France; Member of European Reference Network on Rare Hematological Diseases (ERN-EuroBloodNet), and French Network for Oculo-cerebral Lymphomas (LOC network)

Corresponding author: C. Soussain, Institut Curie, Hématologie, 35 rue Dailly 92210 SaintCloud, France. Phone: (+ 331) 4711 1536. Email: carole.soussain@curie.fr 


\begin{abstract}
Purpose of review: To highlight the diagnostic and management challenges of primary vitreoretinal lymphoma (PVRL) through a review of the literature and a European survey on real-life practices for PVRL.

Recent findings: The care of PVRL patients is heterogeneous between specialists and countries. Upfront systemic treatment based on high-dose methotrexate chemotherapy, with or without local treatment, might reduce or delay the risk of brain relapse.

Ibrutinib, lenalidomide with or without rituximab, and temozolomide are effective for patients with relapsed/refractory PVRL and should be tested as first-line treatments.

Summary: The prognosis of PVRL remains dismal. No firm conclusion regarding optimal treatment can yet be drawn. The risk of brain relapse remains high. Diagnostic procedures and assessment of therapeutic responses need to be homogenized. Collaboration between specialists involved in PVRL and multicentric prospective therapeutic studies are strongly needed. The recommendations of the French group for primary oculocerebral lymphoma (LOC network) are provided, as a basis for further European collaborative work.
\end{abstract}

Keywords: PVRL, diagnosis and management challenges, treatment, guidelines, European mapping 


\section{Introduction}

Primary vitreoretinal lymphoma (PVRL) is a rare subgroup of primary central nervous system lymphoma (PCNSL)(1) with a poor prognosis and unmet medical needs. Diagnosis, treatment, response assessment and follow-up are all challenging. In this context, we aimed to 1) summarize the characteristics of the disease and the main clinical results and to highlight the challenges for this disease, 2) provide the results of a European survey to better assess current practices in real life and 3) provide, as a basis for further European collaborative work, recommendations of the French group for primary oculocerebral lymphoma (LOC network).

\section{Challenges in PVRL}

\section{Definition and characteristics}

PVRL affects the vitreous, retina and exceptionally optic nerve in the absence of brain and systemic involvement. The majority of PVRLs are large B-cell lymphoma, and supposedly, by similarities with PCNSL, of the subgroup with the worst prognosis within the nongerminal center lymphoma group(1,2). PVRLs are distinct from primary uveal marginal zone lymphoma and from secondary intraocular involvement of systemic lymphoma(1). The vitreoretinal involvement encountered at time of the diagnosis of a PCNSL falls outside the definition of PVRL and is beyond the focus of this review.

The estimated incidence of PVRL is 50 cases/year in the US and 10-15 new cases/year in France(3). Patients are mainly immunocompetent adults, with a median age of 70 years(3) and a slight female predominance $(2,4)$.

The pathophysiology of PVRL is still under debate but probably involves the immunosuppressive eye microenvironment(5). An underlying antigen selection is suggested by the finding of a very strong bias in the immunoglobulin gene repertoire, with predominance of the IGHV4-34 gene and a high level of somatic hypermutations(6).

Despite an apparent initial indolent course, PVRL alters vision with an ultimate risk of blindness and has a high tropism for the brain. Indeed, 40 to $90 \%$ of patients with PVRL will develop brain relapse within 30 months after diagnosis $(2,4)$.

\section{Diagnosis}

Patients usually present with insidious onset of symptoms such as floaters and blurred vision. Nonspecific initial symptoms and an initial response to steroids result in delayed diagnosis, with a median time interval from the first symptom of 6 to 40 months(4,7). The main ophthalmological findings(3), bilateral in $2 / 3$ of cases, are clumps of lymphoma cells in the vitreous (well seen in the anterior or peripheral vitreous or along the vitreous) or multifocal cream-colored intraretinal or subretinal spots, which are sometimes associated with retinal pigmentary epithelium alterations, leading to the typical "leopard skin aspect" of the fundus. These infiltrates are well identified by multimodal retinal imaging combining angiography and optical coherence tomography (OCT) (Figure 1).

The diagnosis of PVRL is based on the cytological identification of malignant lymphoid cells in the intraocular samples obtained from a diagnostic vitrectomy and less frequently from retinal biopsy, and/or monotypic B cells on immunocytochemistry and/or flow cytometry $(\mathrm{FCM})(8)$. Polymerase chain reaction can identify monoclonal immunoglobulin heavy chain 
and/or light chain gene rearrangements. Nevertheless, the extreme fragility of lymphoma cells and low cellularity of the samples make diagnosis difficult (Figure 2). When cytology is negative and the clinical suspicion of PVRL is high, a high IL-10/IL-6 ratio in the pure vitreous or aqueous humor (AH), and a high score (ISOLD) based on a logistic regression model, favor a diagnosis of PVRL(9-11). Mutations of MYD88 and CD79B can also be detected in the vitreous $(12,13)$.

To increase the chance of a successful diagnostic vitrectomy, discontinuation of steroids several weeks before vitrectomy, tight collaboration between the ophthalmologist and cytologist/pathologist trained in handling vitreous samples, and immediate analysis of both pure and diluted vitreous samples are critical (Table 1).

Brain, cerebrospinal fluid and extra-CNS lymphoma involvement must be ruled out by a complete initial disease assessment.

\section{Treatment}

The objectives of treatment for PVRL are to clear the intraocular lymphoma, in order to restore the vision of the patient and to prevent CNS relapse, the main cause of death among these patients. The median progression-free survival (PFS) is highly variable across studies $(3,4,7)$, and overall survival (OS) ranges from 58 to 75 months $(3,4)$.

Treatment options range from local treatment by either intravitreal (IVT) injections of chemotherapy or ocular radiotherapy (OR) to systemic PCNSL-like chemotherapies, including intensive chemotherapy with autologous stem cell transplantation (IC+ASCT).

IVT chemotherapy (mainly methotrexate or rituximab(14)) can be used as a first-line treatment or for ocular relapses, alone or in combination with systemic chemotherapies, and is administered according to various schemes (Table 2). Techniques for IVT injection and anterior chamber tap are provided in Table 3.

External beam binocular radiation (30-40 Gy) may be preferred in patients with bilateral disease(2). A reduced dose of irradiation decreases the risk of cataracts and vision-threatening radiation retinopathy $(7,14)$.

Local treatments alone are effective for local control but fail to prevent CNS relapse(2).

First-line systemic treatments remain empirical and are mainly PCNSL-like chemotherapy based on high dose methotrexate (HD-MTX) chemotherapy, with or without whole brain radiotherapy, due to similarities between the blood-brain (BBB) and blood-retinal (BRB) barriers(15), the BRB being even less permeable(16). So far, the analysis of the literature reporting mainly heterogeneous or small series of patients (for a review, see(7)), precluded firm conclusions on the best treatment for PVRL.

The benefit of combining systemic and local treatment to decrease or delay CNS relapse remains equivocal, although suggested in two small cases series(17,18). A recent retrospective French study(3) involving 59 patients homogeneously treated with IV HDMTX-based chemotherapies, but without a local treatment in 51/59 patients, showed an encouraging median brain relapse-free survival of 73 months and an apparent longer median OS (75 months) than that observed in other studies $(3,4)$.

Studies including patients with relapsed or refractory (R/R) PVRL showed that intensive thiotepa-based chemotherapy followed by autologous stem cell transplantation is feasible and effective under the age of 65(7,19). More recently, temozolomide(20) and targeted therapies 
such as lenalidomide, given alone(21) or in combination with rituximab(22), and ibrutinib(23), have shown clinical activity in the intraocular compartment in R/R patients(7). These results encourage to assess the efficacy of temozolomide, lenalidomide or ibrutinib, as single agent either as a salvage treatment before IC+ASCT, or even in first-line treatment.

\section{Response assessment and follow-up}

Assessment of the therapeutic response, by ophthalmological examination and according to criteria used for nodal lymphoma(24), represents a major challenge. Indeed, it remains subjective in the absence of measurable mass(25). Moreover, the distinction between residual disease and active infiltrate can be difficult. The IL-10 level in AH is promising as it parallels the therapeutic response in the vitreous compartment, but a robust correlation between IL-10 levels, CR, PFS or OS is lacking $(3,10,14,22,23,26)$.

The optimal schedule for ophthalmological assessment during treatment and follow-up has not been determined. Disparate patterns of disease monitoring lessen the reliability of the PFS reported in retrospective series. A collaborative approach is essential because systemic chemotherapy prescribed by hematologists or neurooncologists will be guided by ophthalmological examination.

The value of regular, annual and systematic cerebral MRI for the surveillance of brain relapse has never been addressed.

\section{European survey on real-life practice for the management of PVRL}

We performed a short European survey (detailed in supplemental data) to assess current practices in real life for the diagnosis, treatment, response assessment and follow-up of PVRL. Another part of the survey regarded the ophthalmologic follow-up of patients with PCNSL with or without IO involvement, which will not be commented on in this review but presented in supplemental data.

This survey was designed, implemented in a Google form and disseminated from July to November 2020 by the ERN-EuroBloodNet, the European network on rare hematological diseases. Eighty-six responses were obtained from 18 countries (Figure 3A).

\section{Diagnostic procedure}

To establish the diagnosis (Figure 3B), 86\% hematologists/neurooncologists mention fundus and slit lamp examination but less than $40 \%$ referred to angiography or optical coherence tomography (OCT), which is routinely considered by ophthalmologists. Vitrectomy was constantly requested for cytology, but immunohistochemistry or molecular biology were less often required.

$80 \%$ of ophthalmologists but only $27 \%$ hematologists/neurooncologists considered the levels of IL-10 and IL-6 levels in the intraocular liquids as a diagnostic tool.

Cerebral MRI, CSF examination and body CT or body TEP scan are part of $95 \%$ of initial workups, usually organized by hematologists/neurooncologists.

\section{Treatment}

Most of the ophthalmologists $(42 / 45 ; 93 \%)$ requested a multidisciplinary team discussion versus 17/22 (77\%) hematologists/neurooncologists. Ophthalmologists were part of the team in only $45 \%$ of cases. Disparities were identified within and between specialists regarding the 
preferred treatment for PVRL (local, systemic or both) (Figure 3C). No trend could be identified. A slight lesser use of exclusive local treatment was observed among hematologists/neurooncologists.

\section{Response assessment and follow-up}

After treatment (Figure 3D), hematologists/neurooncologists mainly considered slit lamp and fundus examinations (every 3 to 6 months); ophthalmologists also examined OCT (89\%), and angiography (49\%). Cytokine levels in AH was considered by $38 \%$ ophthalmologists, and only few (9\%) hematologists/neurooncologists. Important disparities in the duration of follow-up were observed, from 3 months to lifelong. Systematic surveillance of brain MRI was deemed mandatory by most specialists without a specific schedule.

\section{Expectations highlighted by the survey}

Participants expressed the need for a European network for PVRL to establish guidelines for management $(79 / 86 ; 92 \%)$, provide medical information $(68 / 86 ; 79 \%)$, list expert centers to refer patients or samples $(53 / 86 ; 62 \%)$ and create an online platform for clinical case discussion $(48 / 86 ; 56 \%)$.

In conclusion, this first European survey on PVRL, although not comprehensive, emphasized disparities in clinical practice between physicians and European countries. This highlights the need for closer cooperation between specialists and for establishing guidelines for the care of PVRL patients.

\section{Recommendations of the French national expert LOC network}

The French LOC was created in 2011 to homogenize and improve the care of PCNSL nationwide. National guidelines were issued, based whenever possible on a critical review of the literature $(3,7)$ but also mainly on group consensus because of the lack of robust data in the literature.

We present the guidelines of our group for PVRL as a first step of a potential working basis for European recommendations on PVRL management, as requested by participants of the European survey.

The initial ophthalmological workup should include a fundus and a slit lamp examination, fluorescein angiography and OCT. When a PVRL is suspected, a sample of AH is collected to rule out differential diagnoses and to measure the baseline IL-10 level, which can already favor a diagnosis of PVRL(9-11). Diagnostic vitrectomy is mandatory for diagnosis, completed in rare cases by retinal biopsy. Critical procedures for ocular sampling and their analysis are described in Table 1. Two criteria among typical ophthalmology examination or ocular imaging, cytology, immunohistochemistry, molecular biology, and ISOLD score are requested for a positive diagnosis

The initial workup must also include assessment of the general condition, hematologic, renal and liver functions, cerebral MRI, CSF examination at least for cytology and FCM of lymphoid markers, completed by cytokine level and molecular biology, whole-body CT scan or PET/CT and ideally bone marrow biopsy.

For the treatment of isolated PVRL, the initial 2011 guidelines recommended treating all patients in a fair general condition with IV HD-MTX-based chemotherapy and treating those 
in a worse condition with exclusive local treatment, either ORT or intravitreal-MTX, if CSF involvement had been ruled out.

The results of our cohort of 59 patients(3) treated accordingly revealed a high CR rate $(70 \%)$, a long brain-free survival but a high incidence of intraocular relapse (58\%). This finding might be attributed in part to the close systematic eye monitoring recommended by our network, the absence of local treatment in 51/59 of the cohort patients, and the poor quality of the CR.

Consequently, we updated the guidelines (Table 4) and recommended to add a consolidation by local treatment with low-dose (23.4 Gy) bilateral ORT (Table 5) by extrapolation of what is performed for PCNSL(27). During induction treatment, additional IVTs of methotrexate are recommended if rapid intraocular action is requested (lesions close to the macula). For patients not eligible for IV HD-MTX-based chemotherapy, different options are implemented at the discretion of the physician and include oral temozolomide, IVT-MTX or ORT.

At relapse, second-line treatment based on HD AraC or ifosfamide followed by consolidation by IC+ASCT is considered in those under 65 or up to 70 years of age with adapted IC. Local treatments, as well as ibrutinib, lenalidomide or temozolomide, are considered for patients in poor general condition.

To assess the treatment response, the ophthalmological examination (fundus and slit lamp) is recommended (Table 6), ideally before each cycle of induction chemotherapy (at least every 2 months) at the end of induction treatment, after consolidation treatment and then every 6 months during the first 2 years after treatment and once a year thereafter. Quantification of IL-10 levels in the AH is recommended at baseline, at the end of induction treatment and after consolidation treatment, and in doubt of ocular relapse/progression. OCT and angiography are also recommended at baseline, at the end of treatment and in doubt of ocular relapse. Brain MRI is recommended once a year.

Data being prospectively recorded in our national database, these new practices will be subsequently evaluated.

\section{Conclusion}

PVRL is a challenging disease. The European survey highlights the need to bring together different specialists to homogenize practices and hopefully to design European multicenter prospective studies to improve our knowledge and the outcome of patients with PVRL.

\section{Key points}

Primary vitreoretinal lymphoma is a rare and challenging disease.

The best strategy of treatment to prevent brain involvement is still under debate.

Management disparities are important between hemato-, neuro- and ophthalmologists.

Interleukin dosage is promising for diagnosis and treatment assessment.

Multi-institutional prospective studies are urgently required.

\section{Acknowledgments}

This survey is generated within the European Reference Network on Rare Hematological

Diseases (ERN-EuroBloodNet). FPA 739541. We sincerely thank Maria del Mar Mañú 
Pereira (PhD, ERN-EuroBloodNet Scientific director, Vall d'Hebron Research Institute University Hospital Vall d'Hebron, Spain), Maria de los Ángeles Rodríguez Sánchez (PhD, ERN-EuroBloodNet manager, Vall d'Hebron Research Institute - University Hospital Vall d'Hebron, Spain) and Victoria Gutiérrez Valle (ERN-EuroBloodNet IT and Dissemination Manager, Vall d'Hebron Research Institute - University Hospital Vall d'Hebron, Spain) and the ERN-EuroBloodNet team for their effective help for the design, the dissemination and the analyze of the survey.

Financial support and sponsorship: none.

Conflicts of interest: Choquet S. (Roche, BMS-Celgène, Janssen, Abbvie, Sandoz, Sanofi, Biogaran, Accord Healthcare, Takeda, Atara, Novartis). 


\section{References}

1. Coupland SE, Damato B. Understanding intraocular lymphomas. Clin Exp Ophthalmol. 2008;36(6):564-78.

2. Chan C, Rubenstein JL, Coupland SE, Davis JL, Harbour JW, Johnston PB, et al. Primary Vitreoretinal Lymphoma: A Report from an International Primary Central Nervous System Lymphoma Collaborative Group Symposium. Oncologist. 2011;16(11):1589-99.

*3. Lam M, Touitou V, Choquet S, Cassoux N, Ghesquières H, Kodjikian L, et al. Intravenous high-dose methotrexate based systemic therapy in the treatment of isolated primary vitreoretinal lymphoma: an LOC network study. Am J Hematol. 2021 Apr;

This retrospective study from the French LOC network showed that IV HD-MTX based systemic therapy is feasible in first-line treatment of PVRL, with acceptable toxicity even in an elderly population. It might reduce or delay the risk of brain relapse and prolong overall survival compared to previous published studies. However, despite a high CR rate (70\%), intraocular relapse was frequent (58\%).

4. Grimm SA, Pulido JS, Jahnke K, Schiff D, Hall AJ, Shenkier TN, et al. Primary intraocular lymphoma: An international primary central nervous system lymphoma collaborative group report. Ann Oncol [Internet]. 2007;18(11):1851-5. Available from: https://doi.org/10.1093/annonc/mdm340

5. Touitou V, Daussy C, Bodaghi B, Camelo S, De Kozak Y, Leboang P, et al. Impaired Th1/Tc1 cytokine production of tumor-infiltrating lymphocytes in a model of primary intraocular B-cell lymphoma. Investig Ophthalmol Vis Sci. 2007;48(7):3223-9.

6. Belhouachi N, Xochelli A, Boudjoghra M, Lesty C, Cassoux N, Fardeau C, et al. Primary vitreoretinal lymphomas display a remarkably restricted immunoglobulin gene repertoire. Blood Adv. 2020;4(7):1357-66.

*7. Soussain C, Malaise D, Cassoux N. Primary vitreoretinal lymphoma: A diagnostic and management challenge. Blood. 2021 May 25:blood.2020008235. doi: 10.1182/blood.2020008235. Epub ahead of print. PMID: 34036310.

A comprehensive review of the literature on diagnostic and management challenges of PVRL, highlighting the urgent need for multi-institutional prospective studies. Encouraging results were observed with oral temozolomide, ibrutinib and lenalidomide in patients with relapsed or refractory PVRL, supporting the need to assess these drugs as first-line treatments.

8. Missotten T, Tielemans D, Bromberg JE, Van Hagen PM, Van Lochem EG, Van Dongen JJM, et al. Multicolor flowcytometric immunophenotyping is a valuable tool for detection of intraocular lymphoma. Ophthalmology [Internet]. 2013;120(5):991-6. Available from: http://dx.doi.org/10.1016/j.ophtha.2012.11.007

9. Cassoux N, Giron A, Bodaghi B, Tran THC, Baudet S, Davy F, et al. IL-10 measurement in aqueous humor for screening patients with suspicion of primary intraocular lymphoma. Investig Ophthalmol Vis Sci. 2007;48(7):3253-9.

10. Costopoulos M, Touitou V, Golmard JL, Darugar A, Fisson S, Bonnemye P, et al. ISOLD: A New Highly Sensitive Interleukin Score for Intraocular Lymphoma Diagnosis. Ophthalmology. 2016;123(7):1626-8.

*11. Kuo DE, Wei MM, Knickelbein JE, Armbrust KR, Yeung IYL, Lee AY, et al. Logistic Regression Classification of Primary Vitreoretinal Lymphoma versus Uveitis by Interleukin 6 and Interleukin 10 Levels. Ophthalmology [Internet]. 2020;127(7):956-62. Available from: https://doi.org/10.1016/j.ophtha.2020.01.042

This article validated that intraocular cytokine evaluation (by logistic regression or using the ISOLD score) is helpful for early diagnosis of primary vitreoretinal lymphoma. 
12. Bonzheim I, Giese S, Deuter C, Süsskind D, Zierhut M, Waizel M, et al. High frequency of MYD88 mutations in vitreoretinal B-cell lymphoma: A valuable tool to improve diagnostic yield of vitreous aspirates. Blood. 2015;126(1):76-9.

13. Yonese I, Takase H, Yoshimori M, Onozawa E, Tsuzura A, Miki T, et al. CD79B mutations in primary vitreoretinal lymphoma: Diagnostic and prognostic potential. Eur J Haematol. 2019;102(2):191-6.

14. Pulido JS, Johnston PB, Nowakowski GS, Castellino A, Raja H. The diagnosis and treatment of primary vitreoretinal lymphoma: A review. Int J Retin Vitr [Internet]. 2018;4(1):1-11. Available from: https://doi.org/10.1186/s40942-018-0120-4

15. Matet A, Behar-Cohen F, Cassoux N, Declèves X, Cisternino S. Retinal and choroidal cancers: Blood-retinal barriers considerations in ocular chemotherapy. In: Drug Efflux Pumps in Cancer Resistance Pathways: From Molecular Recognition and Characterization to Possible Inhibition Strategies in Chemotherapy. Elsevier; 2020. p. 303-35.

16. Li Z, Kamon T, Personett DA, Caulfield T, Copland JA, Yoshimitsu T, et al. Pharmacokinetics of Agelastatin A in the central nervous system. Medchemcomm. 2012;3(2):233-7.

17. Hashida N, Nakai K, Saitoh N, Nishida K. Association between ocular findings and preventive therapy with onset of central nervous system involvement in patients with primary vitreoretinal lymphoma. Graefe's Arch Clin Exp Ophthalmol. 2014;252(4):687-93.

18. Kaburaki T, Taoka K, Matsuda J, Yamashita H, Matsuda I, Tsuji H, et al. Combined intravitreal methotrexate and immunochemotherapy followed by reduced-dose whole-brain radiotherapy for newly diagnosed B-cell primary intraocular lymphoma. Br J Haematol. 2017;179(2):246-55.

19. Soussain C, Choquet S, Fourme E, Delgadillo D, Bouabdallah K, Ghesquières H, et al. Intensive chemotherapy with thiotepa, busulfan and cyclophosphamide and hematopoietic stem cell rescue in relapsed or refractory primary central nervous system lymphoma and intraocular lymphoma: A retrospective study of 79 cases. Haematologica. 2012;97(11):1751-6.

*20. Baron M, Belin L, Cassoux N, Fardeau C, Blaizeau M, Soussain C, et al. Temozolomide is effective and well tolerated in patients with primary vitreoretinal lymphoma. Blood. 2020;135(20):1811-5.

In this retrospective multicentric study including 21 patients with relapse/refractory PVRL, temozolomide demonstrated an excellent over all response rate $(81 \%)$ and was well tolerated.

21. Rubenstein JL, Treseler PA, Stewart PJ. Regression of refractory intraocular large B-cell lymphoma with lenalidomide monotherapy. J Clin Oncol Off J Am Soc Clin Oncol. 2011 Jul;29(20):e595-7.

*22. Ghesquieres H, Chevrier M, Laadhari M, Chinot O, Choquet S, Moluçon-Chabrot C, et al. Lenalidomide in combination with intravenous rituximab (REVRI) in relapsed/refractory primary CNS lymphoma or primary intraocular lymphoma: A multicenter prospective "proof of concept" phase II study of the French Oculo-Cerebral lymphoma (LOC) Network and. Ann Oncol. 2019;30(4):621-8.

In this prospective multicentric phase II study including 50 patients with relapse/refractory PCNSL or PVRL (11 patients), lenalidomide in combination with intravenous rituximab showed significant clinical activity in the brain, the cerebrospinal fluid and the intraocular compartments.

*23. Soussain C, Choquet S, Blonski M, Leclercq D, Houillier C, Rezai K, et al. Ibrutinib monotherapy for relapse or refractory primary CNS lymphoma and primary vitreoretinal lymphoma: Final analysis of the phase II 'proof-of-concept' iLOC study by the Lymphoma study association (LYSA) and the French oculo-cerebral lymphoma (LOC) net. Eur J Cancer. 2019;117(June 2017):121-30.

In this prospective multicentric phase II study including 52 patients with relapse/refractory 
PCNSL or PVRL (14 patients), ibrutinib showed significant clinical activity in the brain, the $\mathrm{CSF}$ and the intraocular compartments.

24. Cheson BD, Fisher RI, Barrington SF, Cavalli F, Schwartz LH, Zucca E, et al.

Recommendations for initial evaluation, staging, and response assessment of hodgkin and nonhodgkin lymphoma: The lugano classification. J Clin Oncol. 2014;32(27):3059-67.

25. Abrey LE, Batchelor TT, Ferreri AJM, Gospodarowicz M, Pulczynski EJ, Zucca E, et al. Report of an international workshop to standardize baseline evaluation and response criteria for primary CNS lymphoma. J Clin Oncol Off J Am Soc Clin Oncol. 2005 Aug;23(22):503443.

26. Raja H, Snyder MR, Johnston PB, O’Neill BP, Caraballo JN, Balsanek JG, et al. Effect of Intravitreal Methotrexate and Rituximab on Interleukin-10 Levels in Aqueous Humor of Treated Eyes with Vitreoretinal Lymphoma. PLoS One. 2013;8(6).

27. Morris PG, Correa DD, Yahalom J, Raizer JJ, Schiff D, Grant B, et al. Rituximab, methotrexate, procarbazine, and vincristine followed by consolidation reduced-dose wholebrain radiotherapy and cytarabine in newly diagnosed primary CNS lymphoma: Final results and long-term outcome. J Clin Oncol. 2013;31(31):3971-9.

28. Coupland SE. Analysis of intraocular biopsies. Dev Ophthalmol. 2012;49:96-116.

29. Gonzales JA, Chan C. Biopsy techniques and yields in diagnosing primary intraocular lymphoma. Int Ophthalmol. 2007;27(4):241-50.

30. Merle-Béral H, Davi F, Cassoux N, Baudet S, Colin C, Gourdet T, et al. Biological diagnosis of primary intraocular lymphoma. Br J Haematol. 2004;124(4):469-73.

31. Fishburne BC, Wilson DJ, Rosenbaum JT, Neuwelt EA. Intravitreal methotrexate as an adjunctive treatment of intraocular lymphoma. Arch Ophthalmol (Chicago, Ill 1960). 1997 Sep;115(9):1152-6.

32. Frenkel S, Hendler K, Siegal T, Shalom E, Pe'er J. Intravitreal methotrexate for treating vitreoretinal lymphoma: 10 Years of experience. Br J Ophthalmol. 2008;92(3):383-8.

*33. Zhou X, Zhou X, Shi H, Lai J, Wang Q, Li Y, et al. Reduced frequency of Intravitreal methotrexate injection lowers the risk of Keratopathy in Vitreoretinal lymphoma patients. BMC Ophthalmol. 2020;20(1):1-9.

The authors proposed an interesting scheme of IVT-MTX driven by clinical evaluation resulting in lower number of IVT compared to the standard protocol.

34. Landberg T, Chavaudra J, Dobbs J, Hanks G, Johansson K-A, Möller T, et al. ICRU Report 50. J Int Comm Radiat Units Meas [Internet]. 1993 Sep 1;os26(1):66. Available from: https://doi.org/10.1093/jicru/os26.1.66

35. Landberg T, Chavaudra J, Dobbs J, Gerard J-P, Hanks G, Horiot J-C, et al. ICRU - Report 62. J Int Comm Radiat Units Meas [Internet]. 1999 Nov 1;os32(1):NP-NP. Available from: https://doi.org/10.1093/jicru/os32.1.Report62

36. Yahalom J, Illidge T, Specht L, Hoppe RT, Li YX, Tsang R, et al. Modern radiation therapy for extranodal lymphomas: Field and dose guidelines from the international lymphoma radiation oncology group. Int J Radiat Oncol Biol Phys [Internet]. 2015;92(1):11-31. Available from: http://dx.doi.org/10.1016/j.ijrobp.2015.01.009

37. Nabors LB, Portnow J, Ahluwalia M, Baehring J, Brem H, Brem S, et al. Central Nervous System Cancers, Version 3.2020, NCCN Clinical Practice Guidelines in Oncology. J Natl Compr Canc Netw. 2020 Nov;18(11):1537-70.

38. Fox CP, Phillips EH, Smith J, Linton K, Gallop-Evans E, Hemmaway C, et al. Guidelines for the diagnosis and management of primary central nervous system diffuse large B-cell lymphoma. Br J Haematol. 2019;184(3):348-63. 


\section{Legends}

Figure 1. Ophthalmological findings of primary vitreoretinal lymphoma. A: Wide-field retinal photograph of a right eye showing a blurry fundus due to a dense vitritis (vitreous invaded by lymphoma tumoral cells). B: Wide-field retinal photograph of the left eye of the same patient illustrated in A, showing small yellowish retinal lesions corresponding to the (sub)retinal infiltration by lymphoma cells (white arrow). C. Slit-lamp examination showing a clump of lymphoma cells in the anterior vitreous and along the vitreous fibrils (white arrow). On slit-lamp examination, quiet anterior chamber with no protein flare and some cellular gray diffuse keratic precipitates is usually observed (not illustrated). D. Fluorescein angiography of a patient presenting a primary vitreoretinal lymphoma, showing the lymphoid infiltration as dark spots masking the underlying fluorescence of the choroid (white arrow). Retinal pigmented epithelium (RPE) alterations appear as hyperfluorescent areas due to window effects (yellow arrow). E. Composite color fundus photograph of a patient at the time of diagnosis of a primary vitreoretinal lymphoma, showing more extended and multifocal retinal lesions (white star) than patient presented in B (composite color fundus photograph, photos merged together with built-in camera software). F. Wide-field retinal photograph of the same patient illustrated in $\mathrm{E}$ (dashed lines are the limits of picture E), after treatment. The initial retinal yellowish lesions visible in $\mathrm{E}$ are replaced by areas of RPE alterations (white star). G. Fundus picture showing patchy yellowish subretinal lesions (white star). H: Optical coherence tomography image of the retina along the white line in I showing subretinal hyperreflective deposits of lymphoma cells (white star) that are located between the RPE (yellow arrow) and the Bruch membrane (white arrow).

Figure 2. Example of a large B cell lymphoma on a cytological analysis of a vitreous sample obtained from a diagnostic vitrectomy. Images have a $20 \mathrm{X}$ magnification and were taken from digitalized slide on a Hamamatsu scanner (NDPI format).

A. May-Grünvald-Giemsa staining of a diluted vitrectomy specimen. Cytospin illustrates the low cellularity of the vitreous specimen with rare large lymphoma cells among cellular debris and reactive T cells.

B. Immunocytochemistry with an anti-CD20 antibody (L26 clone Agilent ${ }^{\circledR}$ ) and an anti-CD5 antibody (4C7 clone Novocastra $\left.{ }^{\circledR}\right)$ and Diaminobenzidine (DAB) staining showing the brown positivity for the CD20 and the negativity of the CD5 of the large B lymphoma cells.

C. Immunochemistry with an anti-PAX5 antibody (Clone 24 PAX5 BD Transduction ${ }^{\circledR}$ ) and DAB staining showing the brown positivity for the PAX5 of a large B lymphoma cell.

D. Immunocytochemistry with an anti-CD5 antibody (4C7 clone Novocastra $\left.{ }^{\circledR}\right)$ and Diaminobenzidine (DAB) staining showing the brown positivity for the CD5 of small reactive T-cells.

Figure 3. European survey on real-life practice for the management of PVRL: global information, diagnostic procedure, and response assessment and follow-up. A. On the left graph, percentage of ophthalmologists, hematologists and neurooncologists among survey participants. On the right graph, proportion of survey participants by their place of work. B. Representation of the diagnostic procedures considered by hematologists/neurooncologists and ophthalmologists. Slit lamp and fundus examination were considered by all the ophthalmologists (100\%) and nearly all hematologists/neurooncologists $(86 \%)$. Disparities were also observed. Ophthalmologists frequently considered angiography and OCT (91\% and 98\%, respectively) while less than half of hematologists/neurooncologists considered them (27\% and $41 \%$ respectively). On vitreous samples obtained by diagnostic vitrectomy, immunohistochemistry and molecular biology were less considered than cytology, in both groups. Interleukin dosage in anterior chamber or in vitreous are commonly considered by ophthalmologist ( $80 \%$ ) but only by a few hematologists/neurooncologists (27\%). C. Representation of the preferred first line treatment considered by hematologists/neurooncologists and ophthalmologists. Disparities were identified within and between specialists regarding the choice of a 
local or systemic treatment or both. No real trend can be identified. D. Representation of the techniques considered by hematologists/neurooncologists and ophthalmologists for response assessment and follow-up. Both hematologists/neurooncologists and ophthalmologists mainly considered slit-lamp and fundus examination. Disparities were also observed. Angiography, OCT and interleukin dosage in anterior chamber were considered by only a few hematologists/neurooncologists $(0 \%, 18 \%, 9 \%$, respectively), while a larger proportion of ophthalmologists considered them $(49 \%$, $89 \%, 38 \%$ ). However, OCT and interleukin dosage are less used by ophthalmologists than at diagnosis. Systematic surveillance of brain MRI was deemed mandatory among all specialists.

OCT: optical coherence tomography; AC: anterior chamber. 

Table 1. Procedures for vitreous sampling and analysis

\begin{tabular}{|c|c|c|c|c|}
\hline Before sampling & $\begin{array}{l}\text { Technique for } \\
\text { sampling }\end{array}$ & Eye samples & \multicolumn{2}{|c|}{ Analysis of sample } \\
\hline \multirow{4}{*}{$\begin{array}{l}\text { Inform the } \\
\text { pathologist for } \\
\text { optimal and quick } \\
\text { processing of the } \\
\text { sample after } \\
\text { vitrectomy }\end{array}$} & \multirow{4}{*}{$\begin{array}{l}\text { Gentle diagnostic } \\
\text { vitrectomy } \\
\text { (low cutting } \\
\text { speed) }\end{array}$} & \multirow[t]{2}{*}{ Pure vitreous } & $\begin{array}{c}\text { Cytology } \\
\text { Immunocytochemistry, flow } \\
\text { cytometry*(if enough sample) } \\
\text { Quick shipment to the laboratory at } \\
\text { room temperature to process within } 2 \\
\text { hours after sampling, without fixative }\end{array}$ & $\begin{array}{c}\text { At least } 4 \text { cytospins } \\
2 \text { cytospots for cytomorphological } \\
\text { evaluation after MGG staining } \\
2 \text { cytospots for immunocytochemistry } \\
\text { (alkaline phosphatase or peroxidase) } \\
\text { Use the total amount of the available } \\
\text { material }\end{array}$ \\
\hline & & & $\begin{array}{c}\text { Cytokines (IL-10 and IL-6): 50-100 } \\
\mu \mathrm{L}\end{array}$ & $\begin{array}{c}\text { Storage between }-20^{\circ} \mathrm{C} \text { and }-80^{\circ} \mathrm{C} \text { within } \\
6 \text { hours after sampling } \\
\text { Quantification of cytokine levels in } \\
\text { thawed samples }\end{array}$ \\
\hline & & & \multicolumn{2}{|c|}{$\begin{array}{c}\text { Quick shipment to the laboratory at room temperature to process within } 2 \text { hours } \\
\text { after sampling without fixative. }\end{array}$} \\
\hline & & $\begin{array}{l}\text { Vitreous diluted in } \\
\text { the BSS during the } \\
\text { surgical procedure }\end{array}$ & $\begin{array}{l}\text { Cytomorphology } \\
\text { Immunocytochemistry, } \\
\text { Flow cytometry*, } \\
\text { Molecular biology }\end{array}$ & $\begin{array}{l}2 \text { cytospots for cytomorphological } \\
\text { evaluation after MGG coloration } \\
2 \text { cytospots for immunocytochemistry } \\
\text { (alkaline phosphatase or peroxidase) } \\
\text { Remaining slides stored at }-30^{\circ} \mathrm{C}\end{array}$ \\
\hline
\end{tabular}

MGG: May-Grünwald-Giemsa; IL: interleukin; BSS: balanced salt solution

* To avoid cell death, preservative media could be used (this procedure is currently being assessed)

Adapted from Coupland et al.(28), Gonzales et al.(29) and Merle-Béral et al.(30). 
Table 2. Schemes of intravitreal injections of methotrexate

\begin{tabular}{|c|c|c|c|c|}
\hline & $\begin{array}{l}\text { Dosage of } \\
\text { MTX }\end{array}$ & Induction & Consolidation & Maintenance \\
\hline $\begin{array}{l}\text { First published } \\
\text { protocol(31) }\end{array}$ & $400 \mu \mathrm{g} / 0.1 \mathrm{~mL}$ & $\begin{array}{l}\text { Biweekly until the vitreous is cleared of } \\
\text { cells ( } \pm 1 \text { month) }\end{array}$ & $\begin{array}{l}\text { Weekly for } 4 \\
\text { weeks }\end{array}$ & Once a month for 12 months \\
\hline $\begin{array}{l}\text { "Standard" } \\
\text { protocol(32) }\end{array}$ & $400 \mu \mathrm{g} / 0.1 \mathrm{~mL}$ & Biweekly for 4 weeks & $\begin{array}{l}\text { Weekly for } 8 \\
\text { weeks }\end{array}$ & Once a month for 9 months \\
\hline $\begin{array}{l}\text { "Clinical response } \\
\text { driven" } \\
\text { protocol }(33)\end{array}$ & $400 \mu \mathrm{g} / 0.1 \mathrm{~mL}$ & Biweekly until complete clinical remission* & I & Once a month for 9 months \\
\hline $\begin{array}{l}\text { "Interleukin } \\
\text { response driven" } \\
\text { LOC network } \\
\text { protocol** }\end{array}$ & $400 \mu \mathrm{g} / 0.1 \mathrm{~mL}$ & Biweekly for 4 weeks & / & $\begin{array}{l}\text { If therapeutic response (clinical } \\
\text { amelioration and IL-10<50\% baseline) } \\
* * * \text { : } \\
\text { Once a month until IL-10 negativation } \dagger\end{array}$ \\
\hline
\end{tabular}

MTX: methotrexate

* Defined by the authors as no obvious lesion by slit lamp examination and fundus examination, B-scan echography and optical coherence tomography.

**The aim of this schedule is to reduce the total number of intravitreal injections driven by the level of IL-10 in the aqueous humor. This schedule requires assessing the interleukin level in the aqueous humor at each intravitreal injection of methotrexate and during the follow-up in cases of relapse suspicion.

*** In absence of therapeutic response after induction, IVT of methotrexate are disrupted and a salvage treatment is discussed in multidisciplinary staff meeting.

$†$ IL-10<10 pg/mL. In case of relapse, the induction phase can be started again. 


\section{Table 3. Procedures for intravitreal injection of chemotherapy and anterior chamber tap}

- The two main drugs used for intravitreal injection of chemotherapy are methotrexate $(0.4 \mathrm{mg} / 0.1 \mathrm{~mL})$ and rituximab $(1 \mathrm{mg} / 0.1 \mathrm{~mL})$.

- Anterior chamber tap is performed to collect aqueous humor (IL-10 and IL-6 dosages) to help with PVRL diagnosis and to monitor response to treatment or during the follow-up to assess response or relapse.

- Anterior chamber tap was also performed before each intravitreal injection of chemotherapy to:

$\circ$ Lower intraocular pressure and therefore minimize the risk of reflux of chemotherapy through the injection site

- Monitor IL-10 levels during local treatment by intravitreal injection of chemotherapy.

- Intravitreal injection and anterior chamber tap must be performed in an operating room or a dedicated room for ocular surgery.

- Procedure for anterior chamber tap

o Topical anesthesia using oxybuprocaine or tetracaine drops

- Periocular skin and conjunctival disinfection using 5\% povidone iodine solution (removal of blepharitis if necessary)

- Sterile drape over the patient's face

$\circ$ Eyelid speculum

- Paracentesis at the limbus of approximately $0.1 \mathrm{~mL}$ of aqueous humor using a 32-gauge needle fitted on a $1 \mathrm{~mL}$ syringe. The sample should be immediately frozen in dry ice

$\circ$ Eye irrigation with saline to avoid povidone iodine corneal irritation

- Procedure for intravitreal injection of chemotherapy

○ Preparation of chemotherapy under sterile conditions: methotrexate $(0.4 \mathrm{mg} / 0.1 \mathrm{~mL})$ and rituximab $(1 \mathrm{mg} / 0.1 \mathrm{~mL})$ in a $1 \mathrm{~mL}$ syringe fitted with a 32-gauge needle

- Anterior chamber tap

○ Locating the injection site at $3.5 \mathrm{~mm}$ or $4 \mathrm{~mm}$ to the limbus in cases of pseudophakia or (a) phakia, respectively

- Injection of $0.1 \mathrm{~mL}$ of methotrexate or rituximab. A sterile cotton bud could be used to lower reflux through the injection site.

$\circ$ Generous eye irrigation with saline was performed to avoid chemotherapy and povidone iodine corneal irritation.

IL: interleukin 
Table 4. Guidelines of the French LOC network for the treatment of primary vitreoretinal lymphoma

\section{Primary vitreoretinal lymphoma treatment}

Good general condition* and good renal function

\section{PCNSL-like CT}

(R)-MPVA or (R)-MBVP-A

\pm IVT MTX if rapid action mandatory

Class IIIB

\section{$\mathrm{CR}$}

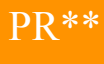

Consolidation ORT

(23.4 Gy/13

fractions)

(Consensus of experts)

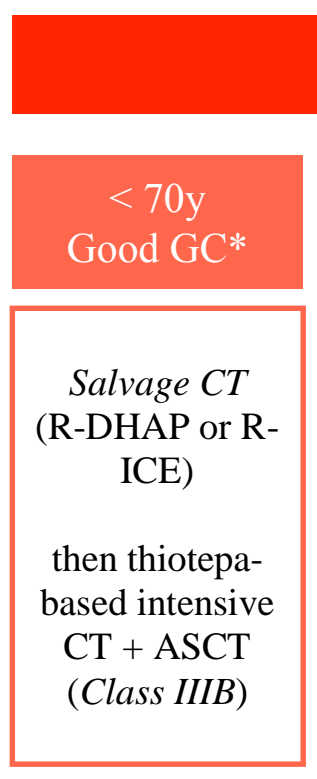

$\mathrm{SD}, \mathrm{PD}, \mathrm{R}$

\begin{tabular}{|c|c|}
\hline \multicolumn{2}{|c|}{$\begin{array}{c}>70 \mathrm{y} \\
\text { Poor general condition }\end{array}$} \\
\hline $\begin{array}{c}\text { Off label } \\
\text { Systemic treatment } \\
\text { Temozolomide } \\
\text { (Class IIIB) } \\
\text { rituximab- } \\
\text { lenalidomide or } \\
\text { ibrutinib } \\
\text { (Class IIIA) }\end{array}$ & $\begin{array}{l}\text { Local treatment } \\
\text { ORT } 30 \mathrm{~Gy} \\
\text { or } \\
\text { IVT MTX } \\
\text { (Class IIIB) }\end{array}$ \\
\hline
\end{tabular}

Poor general condition

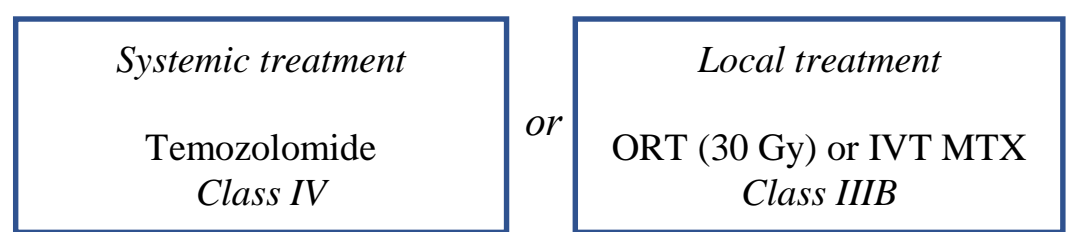

$\mathrm{SD}, \mathrm{PD}, \mathrm{R}$

Local treatment

r

ORT (if not performed

before, $30 \mathrm{~Gy}$ )

or IVT MTX

(Class IIIB)

PCNSL: primary central nervous system lymphoma; CT: chemotherapy; (R)-MPVA: rituximab, methotrexate, vincristine, procarbazine, cytarabine; (R)-MBVPA: rituximab, methotrexate, carmustine, etoposide, prednisone, cytarabine; IVT: intravitreal injection; MTX: methotrexate; ORT: ocular radiotherapy; CR: 
complete response; PR: partial response; SD: stable disease; PD: progressive disease; R: relapse; Good GC: good general condition; R-DHAP: rituximab, dexamethasone, cytarabine, cisplatin; R-ICE: rituximab, ifosfamide, carboplatin, etoposide; ACST: autologous stem cell transplantation.

* Patients with no major comorbidity at the discretion of the clinician.

** PR is defined according to the IPCG criteria(25) but with an undetectable level of IL-10 in aqueous humor.

Scientific evidence was assessed and graded according to the following categories: class I evidence was derived from randomized phase 3 clinical trials;

class IIa evidence derived from randomised phase 2 trials;

class IIb evidence derived from phase 2 trials;

class IIIa evidence derived from prospective studies, including observational studies, cohort studies, and case-control studies;

class IIIb evidence derived from retrospective studies;

and class IV evidence derived from uncontrolled case series, case reports, and expert opinions.

To establish recommendation levels, the following criteria were used: level A required at least one class I study or two consistent class IIa

studies; level B required at least one class IIa study or several class IIb and III studies; level C required at least two consistent class III studies.

When there was insufficient evidence to categorize recommendations in levels $\mathrm{A}-\mathrm{C}$, we classified the recommendation as a consensus of expert 
Table 5. Guidelines of the French LOC network for consolidation ocular radiotherapy

\begin{tabular}{|c|c|}
\hline Patient position & $\begin{array}{l}\text { - } \text { Supine position } \\
\text { - } \quad \text { Customized thermoplastic mask } \\
\text { - } \quad \text { Vertical Reid's base line } \\
\text { - } \text { Closed eyes during CT scan performing. }\end{array}$ \\
\hline Dosimetric CT scan & $\begin{array}{l}\text { - } \quad<2 \mathrm{~mm} \text { slice-thickness } \\
\text { - At } 1 \mathrm{~cm} \text { above the vertex until hyoid bone } \\
\text { - } \quad \text { Iodinated contrast medium not recommended. }\end{array}$ \\
\hline Target volumes & $\begin{array}{l}\text { - CTV: the globe of the eyes not including optic pathway } \\
\text { - PTV: CTV + an isotropic margin in all directions - this } \\
\text { margin should be based upon known departmental values } \\
\text { - } \quad \text { ICRU report \#50(34) \& report \#62(35) }\end{array}$ \\
\hline Organs at risk & $\begin{array}{ll}\text { - } & \text { Brain } \\
\text { - } & \mathrm{L} \text { and R corneas } \\
\text { - } & \mathrm{L} \text { and R lens } \\
\text { - } & \mathrm{L} \text { and R retinas } \\
\text { - } & \mathrm{L} \text { and R optic nerves } \\
\text { - } & \mathrm{L} \text { and R lacrymal glands } \\
\text { - } & \text { Optic chiasma } \\
\text { - } & \text { Pituitary. }\end{array}$ \\
\hline Dose & $\begin{array}{ll}\text { - } & \text { Total dose } 23.4 \mathrm{~Gy} \\
\text { - } & 1.8 \mathrm{~Gy} \text { per day } \\
\text { - } & 13 \text { fractions } \\
\text { - } & 5 \text { times per week } \\
\text { - } & \mathrm{D} 2 \% \leq 25 \mathrm{~Gy} \\
\text { - } & \mathrm{D} 98 \% \geq 22.2 \mathrm{~Gy} . \\
\end{array}$ \\
\hline Technic delivery & $\begin{array}{l}\text { - } \text { Megavoltage equipment - Nominal photon energy } \leq 6 \mathrm{MV} \\
\text { - Three-dimensional conformal radiation therapy (2 opposed } \\
\text { fields) or Intensity-Modulated Radiation Therapy (IMRT). }\end{array}$ \\
\hline Dose constraints & $\begin{array}{l}\text { - } \mathrm{D} 2 \% \leq 23.4 \mathrm{~Gy} \text { for } \\
\circ \quad \mathrm{L} \text { and R corneas } \\
\circ \quad \mathrm{L} \text { and R lacrymal glands } \\
\circ \quad \mathrm{L} \text { and R lens } \\
\circ \quad \mathrm{L} \text { and R optic nerves } \\
\circ \quad \mathrm{L} \text { and R retinas } \\
\circ \quad \text { Optic chiasma } \\
\text { - Planning organ at risk volumes (PRV) are not used. }\end{array}$ \\
\hline Set-up treatment verification & At least weekly by using megavoltage or kilovoltage imaging. \\
\hline Eye set-up verification & Closed eyes during each radiation session. \\
\hline
\end{tabular}

According to. Yahalom et al.(36), the National Comprehensive Cancer Network guideline for central nervous system Cancer (2020)(37) and Fox et al.(38).

CTV: clinical target volume; PTV: planning target volume; ICRU: International Commission on Radiation Units and Measurements; L: left; R: right; D2\%: dose received by $2 \%$ of the planning target volume; D98\%: dose received by $98 \%$ of the planning target volume; MV: mega volt. 
Table 6: Recommendations of the French LOC network for the assessment of the response to treatment in the intraocular compartment

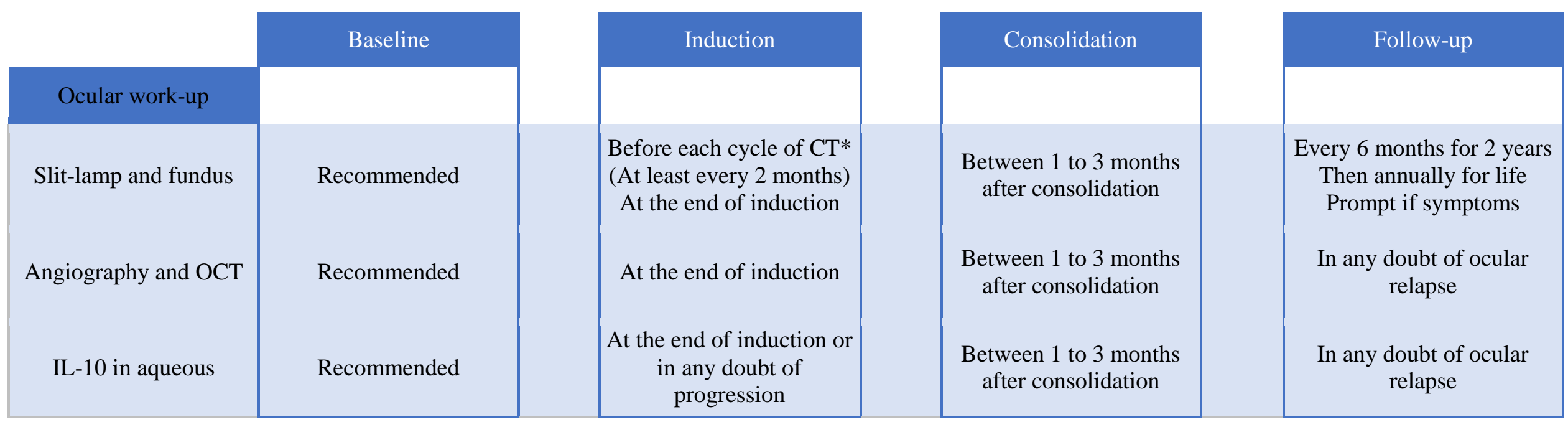

CT: chemotherapy; OCT: optical coherence tomography; IL-10: interleukin 10.

*For nonophthalmologists in charge of treatment, the clinical examination is noninformative for treatment response, and patient-reported symptoms, such as blurred vision or decreased visual acuity, can be misleading because of concomitant dry eyes or cataract. 


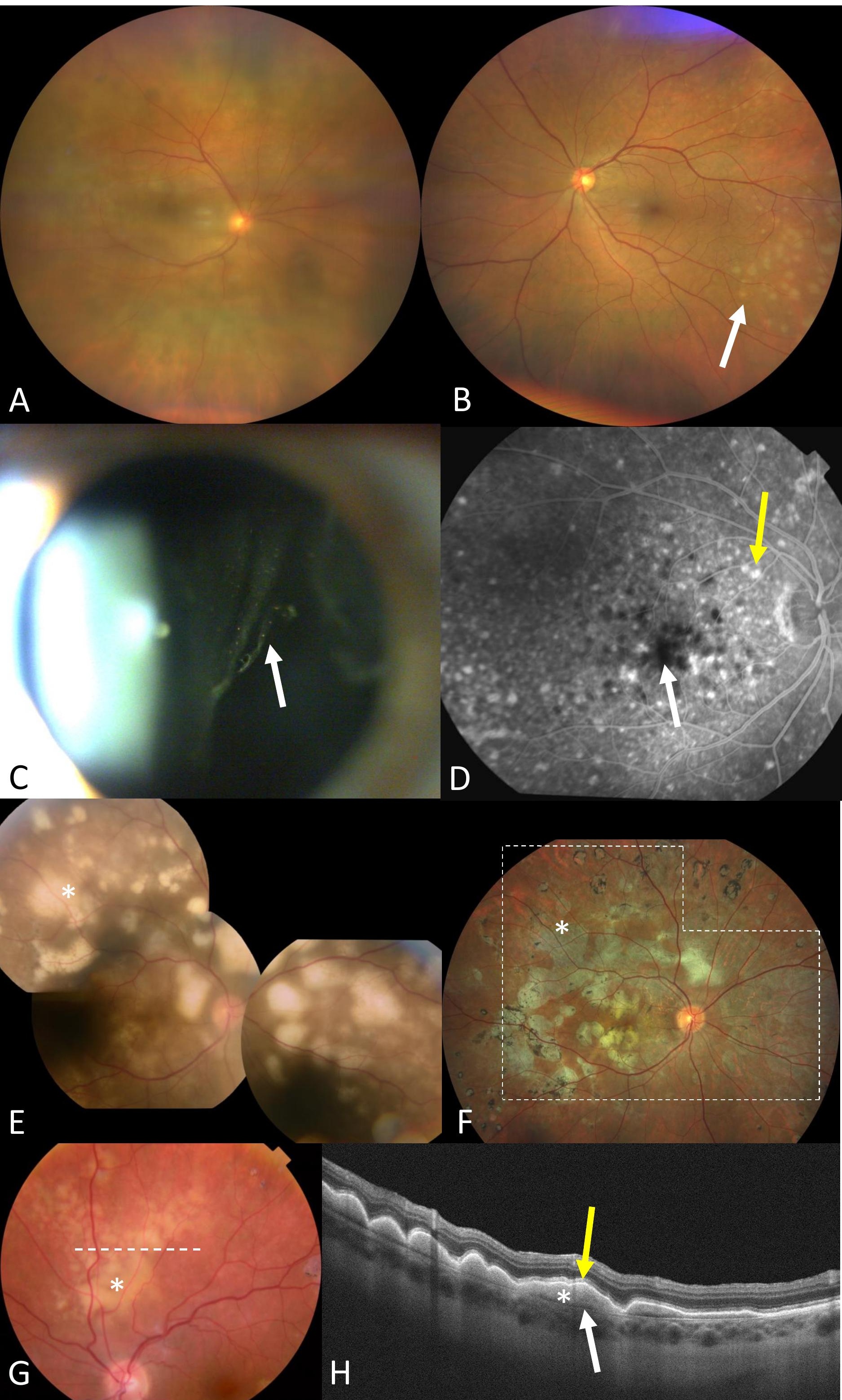


Figure 2

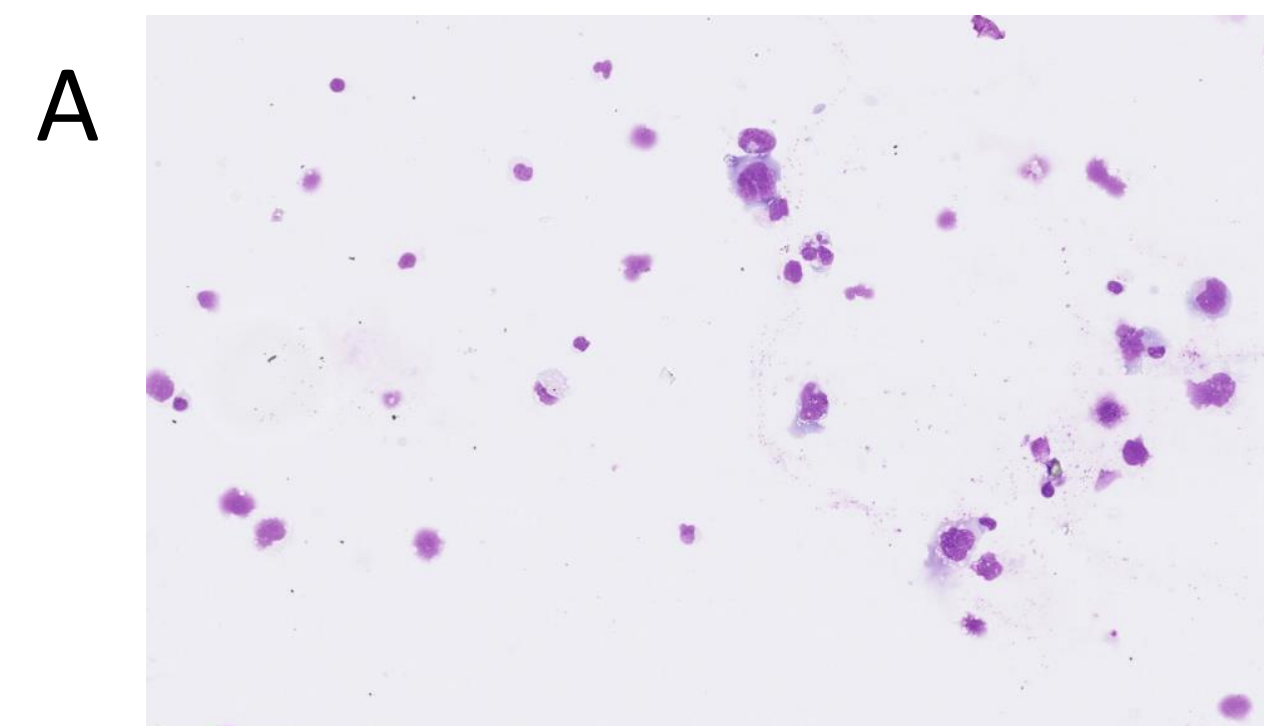

B

C

$$
\therefore \quad \cdots 0^{\circ}
$$

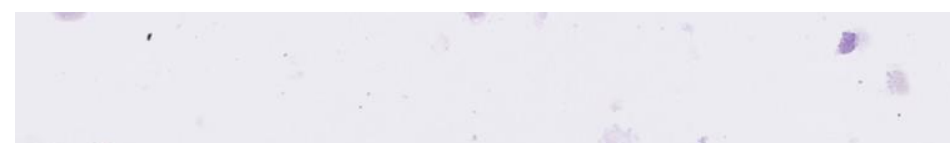

D

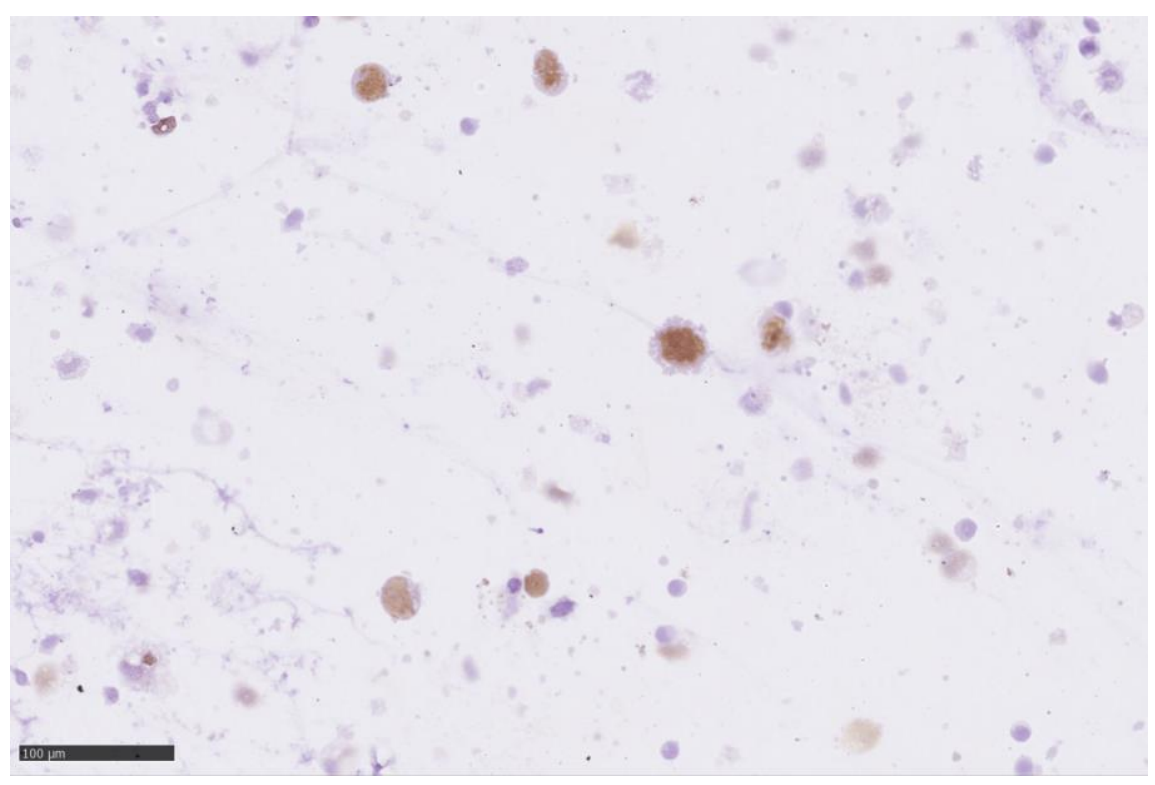



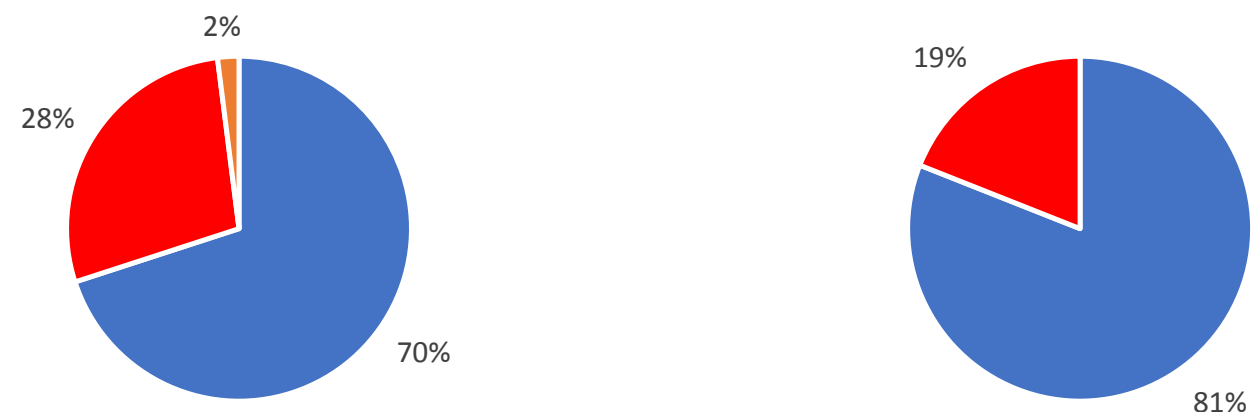

- Ophthalmologists

- Hematologists

- Neurologists

- Public or tertiary referential center

- Private clinic

\section{Diagnostic procedure}

- Hematologists and neurooncologists $(n=22) \quad$ Ophthalmologists $(n=45)$

B

Slit-lamp and fundus examination

Angiography
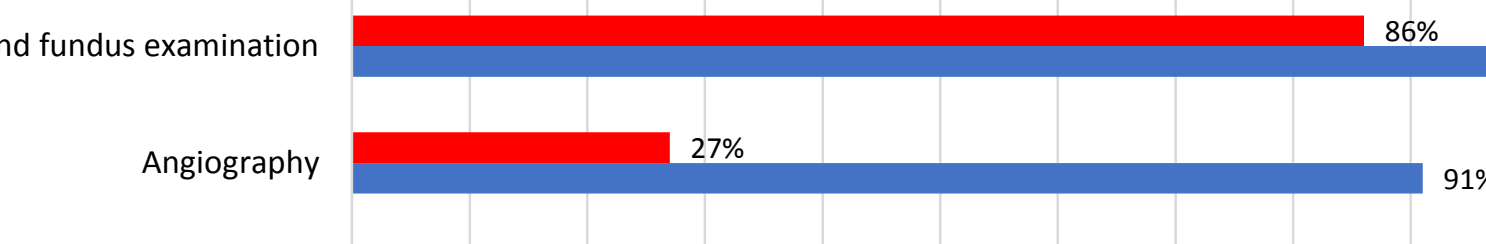

OCT

$41 \%$

Diagnostic vitrectomy

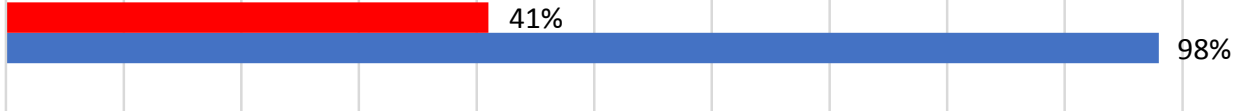

If vitrectomy, cytology
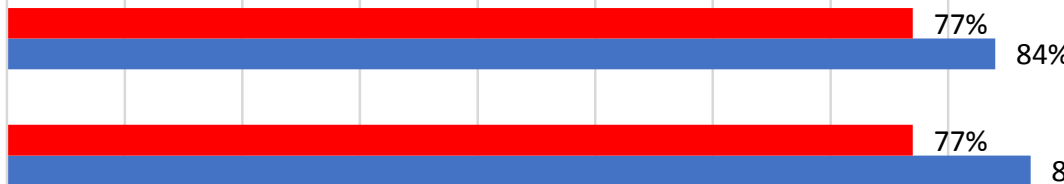

If vitrectomy, immunohistochemistry

If vitrectomy, molecular biology

IL-10 and IL-6 levels in AC or vitreous

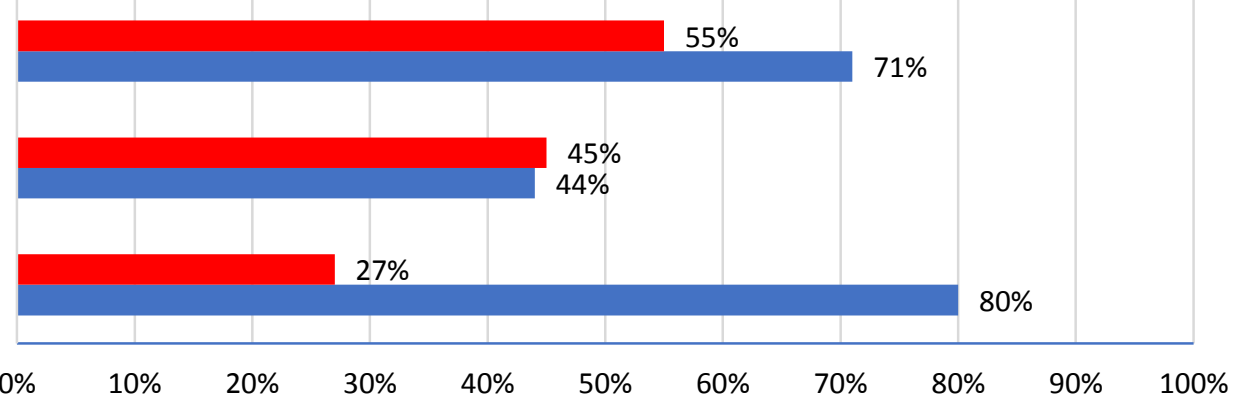

\section{Prefered first-line treatment}

C

Hematologists and neurooncologists $(n=22) \quad$ Ophthalmologists $(n=45)$

Local treatment

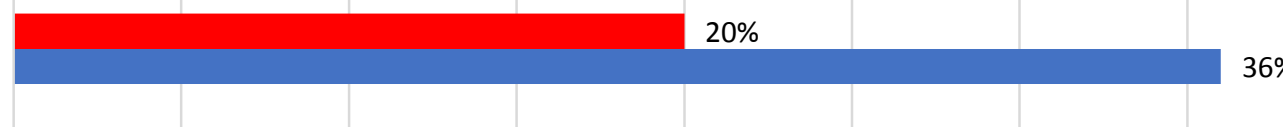

Systemic treatment

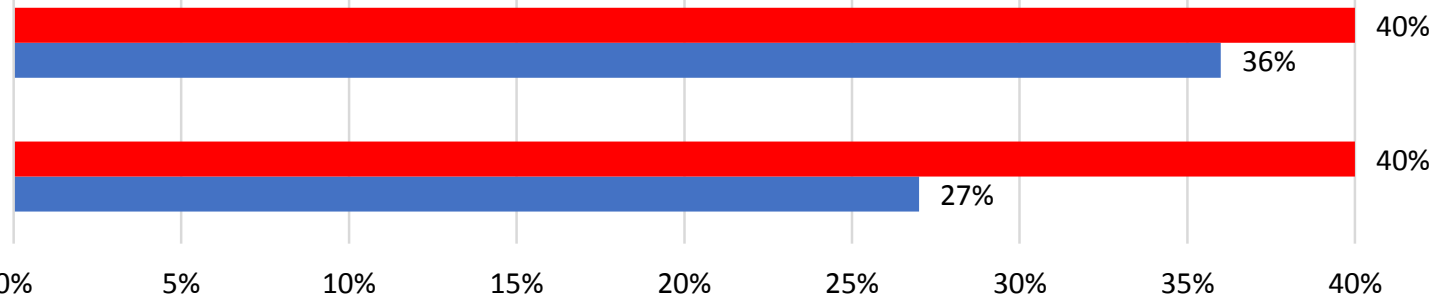

$$
\text { Both }
$$

$0 \%$

$$
5 \%
$$

$10 \%$

\section{Response assessment and follow-up}

- Hematologists and neurooncologists $(n=22) \quad$ Ophthalmologists $(n=45)$

Slit-lamp and fundus examination (3-6 months)

Angiography

OCT

IL-10 and IL-6 levels in anterior chamber

Surveillance for secondary brain involvement

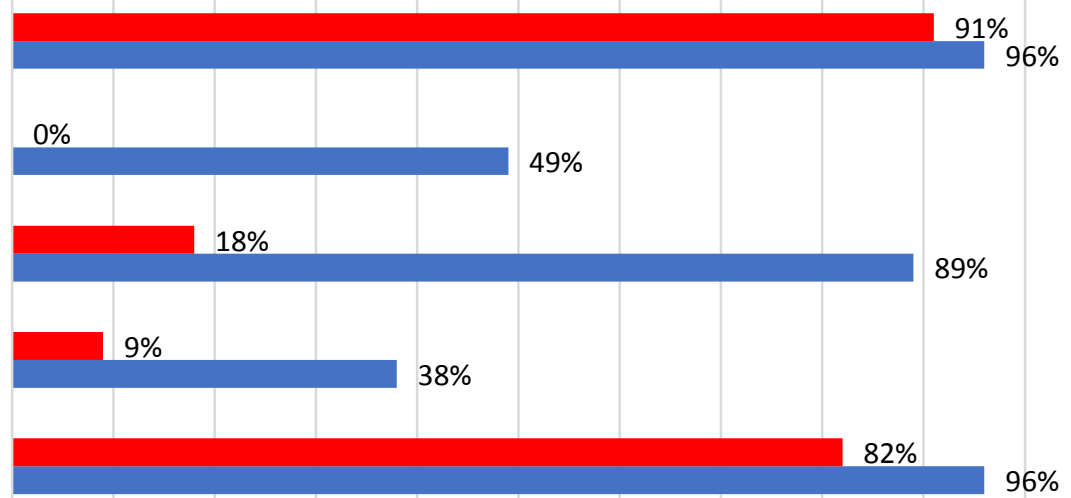


Click here to access/download Supplemental Data File (.doc, .tif, pdf, etc.) PVRL_COO_supplemental_data_2021_05_26.docx 